The Invertebrata : a Manual for the Use of Students By L. A. Borradaile and F. A. Potts. With Chapters by Prof. L. E. S. Eastham and J. T. Saunders. Second edition. Pp. xv+725. (Cambridge: At the University Press, 1935.) 25s. net.

LESS than three years ago (NATURE, 131, 76) we noticed the first edition of this carefully planned volume, each chapter of which has undergone revision by its writer. This edition is eighty pages longer than the first edition, which is largely due to expansion of the general introduction to certain of the sections, and to the insertion of short accounts of animals omitted in the first edition, for example, Piroplasma (Babesia), Gastrotricha, Nematomorpha and Acanthocephala. Other examples of additions which greatly improve the usefulness of the volume are : general observa. tions on the importance to animals of the environ. ment and of the internal medium ; the anatomy and biology of the Metazoa; the general introduction to the Acœlomata; the fuller consideration of feeding and respiration and of the embryology of insects; the extension of the accounts of the Lepidoptera, Hymenoptera and Diptera, and the short summary of digestion in the Cephalopoda. Twenty-nine new illustrations are provided, and, as in the first edition, the chapters on Protozoa, Crustacea and insects are particularly noteworthy for excellence of treatment.

A few of the sections are still unduly short, for example, on the Phoronidea; only one page, half of which is occupied by illustrations, is allotted to this group. There was room on p. 514 to add a brief statement on the parasitic castration produced by the parasite Stylops in its host-the bee.

The assertion that no special sense-organs are known in Brachiopoda is incorrect; statocysts occur in Lingula and at least two other genera. The funnels of the excretory organs in this group and in Arenicola are not regarded as nephrostomes.

The volume, like its predecessor, is a compendium of the most significant knowledge on invertebrates, and the authors well deserve renewed commendation for their clear and concise presentation of the subject.

\section{The Nature of the Physical World}

By Sir Arthur Eddington. (Everyman's Library, No. 922.) Pp. xii +345. (London: J. M. Dent and Sons, Ltd., 1935.) 2s. net.

THrs book is a very welcome and appropriate addition to the modern volumes which have lately been added to the well-known "Everyman's Library". Comment on the work itself is unnecessary: no modern book on scientific philosophy is better known, nor is any collection of standard literature more familiar to the English-speaking public or better appreciated by them.

The introduction, by E. F. Bozman, gives a few comments on the author's life and work which will be helpful to many, but we hope that "Everyman" will read the earlier volumes of his Library in order not to be misled by the reference to "the recent emancipation of thought from the shackles of classical science". In this connexion we cannot refrain from commenting on a remarkable omission from the
Library. In the Science section, containing more than twenty volumes, every science appears to be represented except the oldest-and historically the most influential of all-astronomy; and even now that an astronomer has been selected as an author, it is a non-astronomical work that is chosen. This can scarcely be due to lack of literature. Among the great books of the world there is probably none which, by its combination of historical as well as present-day importance, clarity and cogency of argument, literary merit and intrinsic 'readableness', is more essentially suitable for "Everyman" than Galileo's "Dialogues Concerning the Two Systems of the World". This book is now available to English readers only through Salusbury's original seventeenth-century translation, of which copies are rare and generally unattainable to most of those to whom the book would bring pleasure and profit (and porhaps also emancipation from the shackles of modern paradox). We would suggest that the publishers might consider the possibility of adding this immortal work to the collection.

H. D.

\section{A Dictionary of the Economic Products of the Malay Peninsula}

By I. H. Burkill, with Contributions by William Birtwistle, Dr. Frederick W. Foxworthy, J. B. Scrivenor and J. G. Watson. (Published on behalf of the Governments of the Straits Settlements and Federated Malay States.) Vol. 1: A-H. Pp. xi+ 1220. Vol. 2 : I-Z. Pp. iii +1221-2402. (London: Crown Agents for the Colonies, 1935.) 2 vols., $30 s$.

THIs useful and comprehensive work may well be compared with Sir George Watt's classic "Dictionary of the Economic Products of India", and should stimulate research on Malayan economic products in the same manner that Sir George Watt's well-known work has undoubtedly done for those of India. It is arranged on somewhat similar lines, but is naturally smaller. The author, a well-known botanist, has had a long and varied experience in the Eastern tropics and possesses a first-hand experience of the numerous natural products of these regions. He has been responsible for almost all of what appears in regard to vegetable products in the work-more than ninety per cent of the total. Well-known authorities on mineral, animal, fishery and forest products in Malaya have contributed to the remainder of the subject matter.

The arrangement throughout is alphabetical, vegetable products being placed under the genera to which they belong, while mineral and animal products appear for the most part under their cormmon names. Marginal notes indicating the contents of the text and a good general index, replete with native names, render the work easy of reference. Throughout the text, references to literature are freely quoted.

The author has brought together in convenient and orderly form all the existing information on the uses of the multiplicity of natural products throughout Malaysia. He has also supplied a good deal of information that is new or hitherto unpublished, and is to be congratulated on having performed a great task. 